\title{
A FILOSOFIA POLÍTICA DE TOMÁS DE AQUINO: A NATUREZA HUMANA COMO CENTRO DA ARGUMENTAÇÃO
}

\author{
The political philosophy of Thomas Aquinas: Human Nature as the \\ core of the argumentation
}

\section{Camila Ezídio}

\begin{abstract}
RESUMO
O propósito geral deste artigo é tratar do conceito de natureza humana posta na qualidade de figura central da argumentação política de Tomás de Aquino. A intenção é, em primeiro lugar, apresentar a reinterpretação do naturalismo político aristotélico feita pelo Aquinate. Em segundo lugar, analisar a integração desse naturalismo reinterpretado com as teorias tradicionais do período e à realidade social da Idade Média. E, por fim, compreender em que medida Tomás se afasta das proposições da política clássica, constrói sua reflexão particular, e anuncia alguns temas da política moderna.
\end{abstract}

Palavras-chave: Filosofia Política. Natureza Humana. Tomás de Aquino. Idade Média.

\begin{abstract}
The general purpose of this article is to deal with the concept of human nature posed as a central figure in the Thomas Aquinas' political argumentation. The intention is, primarily, to present the Aquinas' reinterpretation of Aristotelian political naturalism. And, secondly, to analyze the integration of this reinterpreted naturalism with the traditional theories of the period and the social reality of the Middle Ages. And finally, to understand to what extent Thomas departs from the propositions of classical politics, constructs his own particular reflection, and announces some themes of modern politics.
\end{abstract}

Keywords: Political Philosophy. Human Nature. Thomas Aquinas. Middle Ages.

\footnotetext{
${ }^{1}$ Doutora em filosofia e professora temporária na Universidade Federal da Bahia. Esta pesquisa foi realizada com o apoio da FAPESB.

E- mail: camilaezidio@hotmail.com. ORCID: 0000-0002-5783-9574.
} 


\section{Introdução}

É consenso entre pensadores como Ullmann ${ }^{2}$, Skinner $^{3}, B_{\text {Bertelloni }}{ }^{4}$ e tantos outros, a ideia de que a filosofia política da Idade Média, ou ao menos aquela produzida a partir da segunda metade do séc. XIII, apresenta um novo paradigma conceitual ao medievo, se comparada as reflexões da política clássica, cujos postulados serão amplamente reforçados e discutidos na modernidade. $\mathrm{O}$ que chamamos aqui de paradigma conceitual se refere ao conjunto de conceitos apresentados por diversas teorias políticas para a análise e a interpretação do real. Esse conjunto de conceitos é resultado, em primeiro lugar, de uma construção histórica através da recepção das teorias políticas da antiguidade, principalmente da Política de Aristóteles ${ }^{5}$ e, em segundo lugar, da reinterpretação dessas teorias, o que acaba por enunciar as novidades de uma reflexão sobre a política produzida a partir dos anseios e da realidade de uma sociedade medieval ${ }^{6}$.

Além de Aristóteles, é preciso mencionar o importante papel que Agostinho e autores romanos como Cícero, Gaio e Ulpiano exerceram sobre a filosofia política do medievo. No caso dos romanos, mais que teórica, a sua influência foi prática no que toca a jurisprudência. O corpus iuris civilis é, nas palavras de Canning (2011, p. 220), a maior herança da Roma Antiga para a civilização da Europa medieval ${ }^{7}$. Com efeito, surgem muitas refle-

\footnotetext{
2 "A frequente afirmação de que os séculos medievais têm nos tempos modernos uma continuação perfeita adquire uma importância especial referida ao impacto das ideias políticas medievais sobre a formação de conceitos políticos que somente no período moderno conheceram seu completo desenvolvimento." (ULLMANN, 1999, p. 13; trad. nossa); cf. também, ULLMANN, 2010, p. 176.

3 Cf. SKINNER, 1996, p. 71.

${ }^{4}$ Cf. BERTELLONI, 2010, p. 24; 2005, p. 03; 2020, p. 22.

5 Não só os textos de Aristóteles foram recebidos no medievo, mas também um vocabulário e um modo de tratamento das questões éticas e políticas, cf. NEDERMAN, 1996, p. 567. Sobre a influência de Aristóteles na formação do vocabulário político medieval, cf. MARTINS, 2011.

${ }^{6}$ As experiências políticas da Grécia como o berço da democracia do séc. IV - narradas por Aristóteles, sob a perspectiva da justiça, do bem comum e da virtude na construção dos cidadãos - e da pólis são muito distintas das experiências de uma sociedade estratificada com o feudalismo do medievo; cf. SIGMUND, 1993, p. 217.

${ }^{7}$ Sobre a temática, Ullmann diz que, "entre os sistemas jurídicos da Europa medieval, o direito romano assumiu uma importância superior a todos: seu impacto sobre a prática governamental e a ciência era sem paralelo. Isto em parte porque o direito romano era uma expressão madura da mais romana das ideias romanas - a ideia de lei e ordem; em parte pela influência que exercia diretamente ou através da Bíblia; e em parte como o instrumento que forjou relações sociais, moldou hábitos intelectuais e criou um modo de pensar que era único na história da civilização.” (ULLMANN, 2008, p. 53, trad. nossa).
} 
xões, no âmbito da filosofia política medieval, acerca da lei e do direito, como é o caso do Tratado da Lei $^{8}$ de Tomás de Aquino que retoma muitos pressupostos dos filósofos e juristas romanos.

\section{A natureza humana e as teorias políticas medievais}

De forma geral, ao olharmos para textos como a Suma Teológica ou o De Regno 9 , percebemos que uma das principais características da teoria política de Tomás é, sem dúvida, a integração das obras de Aristóteles à cosmologia cristã. Para Ullmann, um dos traços do Estagirita presentes na filosofia tomista é o conceito de natureza considerado tanto sob uma perspectiva física quanto na descrição do homem como tal ${ }^{10}$. Visão semelhante é defendida por Skinner (1996, p. 17), que considera a acolhida e a releitura dos textos aristotélicos um ponto de conciliação entre a concepção política agostiniana cristã, explorada principalmente por autores do séc. XII e da primeira metade do séc. XIII, e a visão autárquica da vida política defendida por Aristóteles. Esse encontro teórico-conceitual é, segundo Skinner, fundamental para o desenrolar da noção naturalista da política na modernidade. Tomás retém a teleologia aristotélica e a visão de que a comunidade política é resultado de uma disposição natural do homem, que é, em suas palavras, "um ser social e político" (TOMÁS DE AQUINO. De Regno I, 1; ed. Busa, 1954, np.) mas, ao mesmo tempo, se mantém fiel a premissa de que a natureza humana é criada e faz parte de um Universo ordenado por Deus. O entendimento que o Aquinate tem do homem é baseado, em primeiro lugar, na consideração de sua natureza, não na fé; o homem e o Cristão

8 O Tratado da lei faz parte da Suma Teológica I-II e representa um conjunto de questões (q. 90-108) que discute desde a própria definição de lei, seus tipos, sua finalidade e suas relações com outras regras morais e políticas, como a virtude.

${ }^{9}$ Abreviações das obras de Tomás de Aquino utilizadas durante este texto: Suma Teológica = ST; Questões disputadas sobre o mal = De Malo; Do Governo dos Príncipes ao Rei de Cipro = De Regno; Comentário à Política de Aristóteles = In Pol. As traduções dos textos de Tomás que aparecem durante este artigo são nossas com alguma comparação as traduções em língua portuguesa, cujas edições são mencionadas na bibliografia.

${ }^{10}$ São muitos os conceitos e temas que foram interpretados pelos historiadores da filosofia como sendo uma influência aristotélica direta na construção da reflexão política do séc. XIII. No entanto, é preciso mencionar que há uma problemática envolvida nessa consideração, que parte do fato de que houve algumas leituras e interpretações feitas dos textos de Aristóteles até a sua chegada ao Medievo. Nederman, em um artigo,"Aristotelianism and the Origins of "political Science" in the Tweltfth Century", trata de fazer uma leitura crítica que destaca a passagem de Aristóteles pelo séc. XII, e consequentemente a releitura de suas obras pelos autores desse período. Ainda sobre a temática, cf. NEDERMAN, 1999, p. 584. 
não são um e o mesmo. Entretanto, isso não quer dizer que se cria uma dicotomia entre eles; pelo contrário, Tomás reconcilia a figura do homem e do Cristão a partir de seu conceito de lei natural, que representa a participação da lei eterna na criatura racional ${ }^{11}$. Contudo, apesar dessa reconciliação, o ponto central permanece: a natureza humana, por meio de suas aptidões racionais, reconhece suas necessidades e tem a capacidade de dirigir e ordenar a si própria.

A razão natural, de acordo com Tomás, opera sem qualquer revelação ou graça e se destaca da ratio fide informata. Tudo isso é na substância consequência de uma "teologia natural" corretamente entendida, que se preocupa com a explicação dos fenômenos naturais, eles mesmos emanação da criação divina. $\mathrm{O}$ homem constitui parte deles [...] (ULLMANN, 2010, p.169).

O conceito de natureza permitiu, segundo Ullmann, que Tomás fizesse a distinção moral entre o bom homem e o bom cidadão e que ele construísse uma teoria sobre a comunidade política que, a partir do naturalismo aristotélico, lidasse com as relações sociais ali dadas e com a questão do governo humano desde que este passou a ser entendido como distinto da Divina Providência. Partindo das premissas aristotélicas, a cidade é, segundo Tomás, resultado da disposição natural humana que, por meio de comunidades menores, atinge aquela que será responsável pela realização terrena ${ }^{12} \mathrm{da}$ natureza do homem, a saber, a pólis, a civitas ou a comunidade perfeitíssi$\mathrm{ma}^{13}$. Não há qualquer interferência direta da graça divina nesse processo de composição e operação da sociedade humana; a cidade é criada a partir da própria disposição humana, e as leis positivas que ali legislam devem ser

${ }^{11}$ Cf. TOMÁS DE AQUINO. ST I-II, q. 91, a.2, res; ed. Leonina t.7, 1892, p. 154.

${ }^{12}$ A ideia de realização da natureza humana perpassa, desde Aristóteles (cf. ARISTÓTELES. Ética à Nicômaco, I), o conceito de felicidade, no entanto, para Tomás, a "felicidade" possui dois significados: o primeiro se refere a uma felicidade imperfeita (felicitas), relacionada a tudo aquilo que os homens podem alcançar na vida terrena; o segundo se refere a uma felicidade perfeita, relacionada a tudo o que os homens podem alcançar se escolhidos por Deus (beatitudo). De acordo com o professor Alfredo Storck: "a felicidade [alcançada na civitas] consiste no conjunto de bens alcançados durante uma vida desfrutada em concordância com determinados preceitos da virtude.” (1995, p. 541). Com efeito, sendo a lei a regra que ordena os atos das virtudes (Cf. TOMÁS DE AQUINO. ST I-II, q.94, a.3, res; ed. Leonina t.7, 1892, p.170), a felicidade, no sentido imperfeito, é alcançada por meio de ações ordenadas pela lei na civitas.

13 Segundo Tomás, a cidade se configura como a comunidade perfeita (perfecta communitas) que terá as condições de conduzir o homem ao mais alto dos bens dentre todos os bens humanos. Cf. TOMÁS DE AQUINO. In Pol., I, lec.1; ed. Busa, 1971, n. 23. Para mais referências sobre o assunto Cf.: TOMÁS DE AQUINO. ST I-II, q.90, a.3, res; ed. Leonina t.7, 1892, p. 149; ST II-II, q.50, a.1, res; ed. Leonina t.8, 1895, p. 374. 
leis derivadas da lei natura $1^{14}$, a fim de serem leis justas ao estarem de acordo com a natureza humana.

Uma vez que a natureza humana se caracteriza como o centro da argumentação da filosofia ética e política de Tomás de Aquino, é preciso investigar o que o filósofo entende por tal conceito. Segundo o professor Francisco Bertelloni, a concepção de natura sofreu algumas mudanças durante a Idade Média o que acarretou alterações também nas teorias políticas produzidas nesse período. Bertelloni entende que a natureza é

"modelo de conhecimento", porque ela constitui um conjunto de informações que se articulam entre si como princípio explicativo único da operação e do movimento da realidade que nos permite conhecê-la em sua totalidade. (BERTELLONI, 2011, p. 12; trad. nossa).

Em outras palavras, a natureza representa tanto um grupo de coisas e fenômenos, como a normatividade imposta aos mesmos. Em Tomás encontramos a seguinte definição:

a palavra natureza se impôs primeiramente para significar a geração dos seres vivos, que se chama nascimento. E como tal geração provém de um princípio intrínseco, estendeu-se o uso da palavra para significar princípio intrínseco de qualquer movimento. (TOMÁS DE AQUINO. ST I, 29,1 ad. 4).

Quanto ao seres humanos, Tomás diz que "a razão é a natureza do homem" (TOMÁS DE AQUINO. De Malo, q.14, a.2 ad. 8), aproximando-se assim da definição geral e física de natureza dada acima, na medida em que a razão é a causa intrínseca responsável pela direção e ordenamento do ser humano por intermédio da lei, o que poderia significar uma espécie de movimento, ao menos no sentido qualitativo, em relação às ações humanas. Para reforçar tal posicionamento, Tomás declara em outro momento que "os princípios da razão são os mesmos que estruturam a natureza" (TOMÁS DE AQUINO. ST II-II, q.154, a.12, res.), denotando, com isso, a similaridade entre a normatividade da organização do cosmos e do ser.

Há três principais momentos pelos quais passou o conceito de natura no medievo. O primeiro vai até o século XII, quando a natureza exercia uma função simbólica, pois era entendida como um conjunto de coisas do

\footnotetext{
14 Sobre o processo de “derivação” da lei humana a partir da lei natural, cf. TOMÁs DE AQUINO. ST I-II, q.95, a.2, res; ed. Leonina, 1882, p. 174.
} 
mundo sensível que pura e simplesmente representava toda a sabedoria e a vontade Divina. No segundo momento, a natureza era entendida a partir da esfera de ordenamento e legalidade que Deus infligia sobre as coisas. O terceiro momento acontece com a recepção de Aristóteles no medievo. A natureza é apresentada pelo Estagirita a partir de uma noção teleológica, na qual cada coisa que a compõe está ordenada a um fim, o qual era entendido como a perfeição ou a realização da "natureza" dessa coisa. Segundo Bertelloni (2011, p.13), embora a tradição platônica e estoica já tivesse deixado as bases para a interpretação de uma natureza normativa, Aristóteles trouxe um naturalismo teleológico que permeou toda a realidade física e humana, construindo, portanto, a visão de uma natureza que se manifestava como princípio constitutivo e causa final. Entretanto, dentro desse terceiro momento e simultaneamente a essa terceira posição, despontou uma outra, que entendia a natureza mediante a síntese entre Aristóteles e o conceito de lei natural estoico $^{15}$ recebido por Cícero e Santo Agostinho. Dessa composição, nasceu uma natureza entendida em dois sentidos: por um lado, como ordenamento intrínseco de cada coisa e, por outro lado, como um ordenamento universal, entendido por Cícero como sendo uma ratio eterna ${ }^{16}$ e por Santo Agostinho como sendo a lei eterna ${ }^{17}$. De acordo com Bertelloni,

este naturalismo, cujo representante mais emblemático é talvez Tomás de Aquino, recebe de Aristóteles a physis própria de cada indivíduo, mas acrescenta que cada coisa tem sua própria physis porque existe uma legalidade universal equivalente à razão divina ou lei eterna que opera como sua causa. (BERTELLONI, 2020, p. 28; trad. nossa).

A physis, ou a natura, de cada indivíduo é entendida por Tomás de Aquino sob os parâmetros da lei natural. Dito de outro modo, a natureza humana, por meio da sua racionalidade, manifesta-se ordenadamente a partir de uma lei que lhe é, ao mesmo tempo, intrínseca e intermediária para com a lei eterna e o ordenamento Universal Divino: “assim como a ordem da razão

\footnotetext{
15 Sobre o tema, cf. BOERI, 2013.

16 “[...] que a lei não foi pensada por mentes humanas; que não é alguma legislação de assembleias populares; mas é algo eterno." (CÍCERO. Das Leis, II, 4; ed. Muller, 1915, p. 407; trad. nossa.).

${ }^{17}$ A verdadeira lei eterna não é senão a razão divina ou a vontade de Deus, determinando que a ordem natural seja mantida." (AGOSTINHO. Contra Fausto Maniqueu, XXII, 27; ed. PL 42, p. 418; trad. nossa)
} 
reta procede do homem, assim também a ordem da natureza procede do próprio Deus" (TOMÁS DE AQUINO. ST II-II, q. 154, a.12, ad.1).

A incorporação do naturalismo na filosofia política possibilitou, a princípio, duas leituras: de um lado, os que pensavam que o naturalismo aristotélico era a única fonte teórica e, de outro, os que acreditavam que houve uma soma de diversos naturalismos. A primeira leitura é a mais comum e tem consequências, digamos que, errôneas, na visão de Bertelloni. Segundo o autor, duas máximas aristotélicas que estão presentes em muitos dos textos de filosofia política do medievo são as seguintes: o homem é por natureza um animal político e a cidade é também natural ${ }^{18}$. O problema é que muitos filósofos utilizaram tais proposições em conjunto com outras, agregando, assim, um novo sentido e uma nova interpretação à natura aristotélica. Dessa maneira, embora a fonte das teorias políticas medievais tenha sido Aristóteles, para Bertelloni (2011, p. 16), havia, ao mesmo tempo, uma proximidade e um distanciamento entre elas. Criou-se a ideia comum de que, depois de Tomás de Aquino, todas as teorias políticas carregavam um naturalismo aristotélico, o que levou a um grande esforço para mostrar a relação essencial entre esse naturalismo e as reflexões políticas medievais, culminado, assim, no chamado naturalismo político aristotélico-tomista. Tal expressão, para Bertelloni, não descreve a realidade, pois as teorias políticas da Idade Média, e em particular a de Tomás de Aquino, não se constroem unicamente sobre a filosofia aristotélica e não negam a teologia, mas abrangem ambas as esferas do conhecimento e da realidade.

Segundo Nederman (1988, p. 03), é fato que não se pode desconsiderar que a proposição de que o homem é naturalmente social e político faz parte da filosofia política produzida na Idade Média. Entretanto, assim como Bertelloni, o autor acredita que a unanimidade de uso da proposição entre os pensadores não abrange a sua interpretação, pois cada filósofo entende a natureza social e política do homem a seu modo. O uso comum da ideia pode se justificar, em certa medida, pelas fontes também comuns que foram utilizadas no medievo. Uma dessas fontes, comos sabemos, é Aristóteles, o qual se supôs, por um período, ser o único autor cujo naturalismo social e político influenciou os medievais. No entanto, percebeu-se que havia outros pen-

18 ARISTÓTELES. Política, I, 1, 1252 b 26 -1253a 3; trad. Amaral e Gomes, 1998, p. 53. 
sadores, como Cícero, Sêneca e Agostinho que, a seu modo, partilhavam um pensamento parecido no que toca a natureza humana.

O naturalismo social e político não é somente uma fonte teórica para os autores medievais, mas é também um problema filosófico, uma vez que havia um contexto Teológico-Cristão no qual a natureza humana estava inserida. Para o Cristianismo, a natureza do homem havia sido punida por conta do pecado, e, por isso, alterada de seu estágio original. O homem tornou-se, após a queda, egoísta e mal, características que não estão de acordo com uma natureza social. De que maneira então a natureza humana decaída e má continuava a ser entendida pelos filósofos medievais como a fonte da comunidade política que preza pelo bem comum?

Agostinho, na Cidade de Deus, descreve o homem do seguinte modo: "Nenhuma raça é tão dada à discórdia por sua degradação, nem tão sociável por natureza." (AGOSTINHO. A Cidade De Deus, XII, 27; ed. PL 41, p. 375; trad. Pereira, 2016, p. 1153). Vejamos que, para o autor, a natureza humana em seu estado original é social, mas esse caráter é corrompido pelo pecado. Entretanto, a queda não destruiu toda a estrutura ontológica dessa natureza, e, por isso, é possível considerar ainda algum impulso de convivência entre os homens. De acordo com Nederman (1988, p. 04), da problemática de conciliar o aspecto social da natureza humana com o caráter destrutivo do pecado, surgem duas principais linhas teóricas na discussão política. Uma segue Agostinho e postula que a vida política estruturada na cidade não é resultado da natureza humana em si mesma, mas, na verdade, é fruto da necessidade de um poder coercitivo sobre essa natureza decaída. Portanto, a cidade, suas relações e instituições não são naturais ao homem em seu estado pleno, mas se tornam essenciais a sua natureza pós-pecado ${ }^{19}$. A outra linha teórica segue Aristóteles e propõe que a sociedade política é resultado da associação natural do homem; as comunidades menores, como a família e a aldeia, convertem-se, em última instância, na cidade. Com suas estruturas e instituições, a cidade oferece o espaço para a realização da natureza humana tanto quanto é possível no mundo terreno.

\footnotetext{
19 “[...] a sociedade dos Anjos e dos homens ímpios, avançando para o Deus vivo pelas sendas da fé, que opera pela caridade[...]" (AGOSTINHO. A Cidade de Deus, XVIII, 18; ed. PL 41, p. 574; trad. Pereira, 2016, p. 1739).
} 
Segundo Nederman (1988, p. 05), grande parte dos autores medievais se dividiram entre essas duas linhas de pensamento. No entanto, apoiada nos escritos de Cícero, configura-se uma terceira linha teórica que une a doutrina do pecado e a ideia de que a natureza humana conserva sua inclinação à associação mesmo após a queda. De acordo com essa visão ciceroniana, os homens se unem ao reconhecerem ${ }^{20}$ as estruturas comuns de sua natureza e com isso suas necessidades. A origem da sociedade está fundamentada na percepção da racionalidade e na capacidade de discurso humana. Enquanto a primeira induz os seres a viverem em grupo, a segunda proporciona-lhes as condições para tanto ${ }^{21}$. Tal processo caracteriza-se tanto como convencionalista quanto como naturalista, visto que, ao mesmo tempo, mantém a associação entre os homens ligada à natureza humana, mas a entende como necessária ${ }^{22}$.

É possível dizer que Tomás não é adepto de nenhum dos extremos, isto é, não há a presença única de um "aristotelismo puro" ou de um "agostinismo político" ou de uma visão sobre os padrões "ciceronianos" na descrição da natureza humana e mesmo no entendimento da comunidade política. O que se pode perceber, entretanto, é que o Aquinate transita entre os autores. Primeiro, porque mantém a ligação com a tradição e, consequentemente, com Agostinho, a partir da compreensão de uma natureza humana criada, decaída e ordenada extrinsecamente por uma lei eterna ${ }^{23}$; segundo, porque postula a ideia de uma lei natural ${ }^{24}$ que carrega o pressuposto teleológico aristotélico de conduzir intrinsecamente a natureza humana à vida na comunidade política ${ }^{25}$; terceiro, porque entende, a partir de Cícero, que a comuni-

${ }^{20}$ Cf. CÍCERO. Dos Fins, III, 19,62-64. ed. Schiche, 1915, 25-18, p. 113-114.

21 "[...] a origem da coisa que chamamos eloquência [...] encontramos seu surgimento nas mais honoráveis causas." (CÍCERO. Da Invenção, I,1,2; trad. nossa).

22 "Consequentemente, a doutrina dos "Ciceronianos medievais" representa uma espécie de via media entre os extremos do ponto de vista agostiniano e aristotélico: ela atribui ao pecado um lugar central ao afirmar que os homens se comportam de forma antissocial porque não reconhecem as consequências de sua natureza comum; mas também admite que a propensão humana natural para se associar continua a ser eficaz mesmo no estado pós-lapsariano de iniquidade." (NEDERMAN, 1988, p. 05; trad. nossa).

23 Sobre a lei eterna em Agostinho, cf.CHROUST, 1950. Em Tomás, cf: TOMÁS DE AQUINO. ST I-II, q. 93, a.5.

${ }^{24} \mathrm{Em}$ resumo, a lei natural é um princípio intrínseco, moral e político, promulgado pela e para a própria razão humana com vistas a reger e ordenar as ações dos homens em relação a aquilo que é bom para sua natureza.

${ }^{25}$ Sobre os preceitos da lei natural, cf. TOMÁS DE AQUINO. ST I-II, q. 94, a. 2, res; ed. Leonina t.7, 1892, p.170. 
dade é um espaço que, apesar de ter um princípio natural, requer alguns acordos e leis, que se manifestam por meio da linguagem ${ }^{26}$ e garantem a ordem e a manutenção do espaço político ${ }^{27}$, no qual as necessidades da vida humana se dão e podem ser supridas ${ }^{28}$.

\section{Tomás de Aquino: a reinterpretação da concepção de natureza humana}

Até o momento tratamos de algumas concepções acerca da natureza humana que são retomadas no medievo por Tomás de Aquino. No entanto, nos resta saber qual a distinção e, consequentemente, a novidade entre essas concepções clássicas e a teoria política de Tomás de Aquino. Na Suma Teológica I, q. 96, a.4, Tomás apresenta, através de uma discussão acerca do domínio político, 1- a diferença entre a sua concepção de natureza humana e a de Agostinho e, 2- a sua reinterpretação do conceito de natureza aristotélico. O problema central do artigo é discutir se antes do pecado, isto é, no estado de inocência, havia vínculos de subordinação entre os homens. A defesa de Agostinho é de que no estado de inocência não havia qualquer tipo de dominação de um homem sobre o outro, pois esse estado, anterior ao pecado, é um estado puro que expressa de modo pleno a natureza dos seres humanos. Todavia, com o pecado, a natureza cai, corrompe-se, mas pode vir a ser restaurada $^{29}$ através do governo terreno. Com efeito, apesar de o filósofo assumir que a sociabilidade é conatural ao homem ${ }^{30}$, na medida em que esse cria laços familiares e de amizade, as relações de domínio que culminam na

\footnotetext{
26 “[...] o uso da fala é uma prerrogativa própria do homem. Por este meio, um homem é capaz de expressar plenamente as suas concepções aos outros [...]" (TOMÁS DE AQUINO. De Regno, I, 1; ed. Busa, 1954, np).

27 “[...], portanto, foi necessário para a paz e virtude dos homens, que as leis fossem impostas.” (TOMÁS DE AQUINO. ST I-II, q.95, a. 1, res; ed. Leonina t.7, 1892, p.174).

28 "Portanto, é necessário que o homem viva em uma multidão para que cada um possa ajudar seus semelhantes, e diferentes homens possam estar ocupados em buscar, por sua razão, fazer diferentes descobertas.” (TOMÁS DE AQUINO. De Regno, I, 1; ed. Busa, 1954, np).

29 "Mas como a própria parte mental, sede natural da razão e da inteligência, está muito debilitada pelos vícios inveterados que a obscurecem necessitaval antes de tudo, de ser purificada pela fé para aderir à. luz imutável e dela gozar ou mesmo para lhe suportar o esplendor, até que, renovada e curada dia a dia, se torne capaz duma tão grande felicidade." (AGOSTINHO. A Cidade de Deus, XI, 2; ed. PL 41, p. 318; trad. Pereira, 2016, p. 990).

30 "Foi por isso que o criou único e só, não certamente para o deixar isolado de toda a sociedade humana, mas para pôr mais em relevo a seus olhos o vínculo de unidade e concórdia que esta sociedade deve manter, estando os homens ligados entre si pela identidade de natureza e pelos vínculos afectivos de parentesco." (AGOSTINHO. A Cidade De Deus, XII, 21; ed. PL 41, p. 372; trad. Pereira, 2016, p.1140).
} 
ideia de uma comunidade política não fazem parte da estrutura ontológica da natureza humana.

Para Tomás, ao contrário do que propõe Agostinho, o dominium no sentido político ${ }^{31}$ é possível mesmo no estado de inocência do homem. Tomás entende, a partir de uma reformulação do naturalismo aristotélico, que o homem é naturalmente um animal social que vivia em grupo desde o estado de inocência e, que essa configuração natural da vida entre muitos requeria alguém que conduzisse de modo ordenado a sociedade; como explica o próprio Tomás, "não poderia haver vida social de muitos a não ser que alguém presidisse, tendo a intenção do bem comum.” (TOMÁS DE AQUINO. ST I, q.96, a.4, res; ed. Leonina, t.5, 1889, p. 430). Portanto, o dominium, entendido como governo, não é incompatível com o estado de inocência, porque não contradiz qualquer característica ontológica da natureza humana, ao contrário, é devido ao seu aspecto intrinsecamente social que a subordinação de um homem sobre o outro é possível.

De acordo com Bertelloni (2009, p. 06), a afirmação da sociabilidade humana é um critério que, além de afirmar a possibilidade de existência do dominium político, distingue a visão de Tomás em relação à de Aristóteles e à de seu zoon politikon. Ademais, essa não é pura e simplesmente uma distinção, mas, na realidade, a descrição da passagem da natureza humana de seu estado social para seu estado político. Segundo a professora Ferreiro (2010, p. 56), o argumento sobre o dominium no sentido político é fruto de uma releitura da premissa aristotélica de que o homem é um animal político por natureza, a partir da qual Tomás afirma o caráter natural da sociabilidade humana e pontua que essa vida social não seria possível se não houvesse um líder que governasse com vistas ao fim comum ${ }^{32}$.

\footnotetext{
31 De acordo com Tomás de Aquino, há dois sentidos nos quais o domínio (dominium) pode ser entendido, sendo eles: a servidão e o governo. No primeiro caso, a relação se dá entre um homem livre e um homem não livre, isto é, entre um senhor e um servo. Nessa relação, o dominium é estabelecido pela utilidade que o dominado tem para o dominador; por conseguinte, o bem apetecido nessa relação é o bem do senhor e não do servo. Já o dominum em sentido de governo acontece entre homens livres, quando aquele que domina dirige o dominado para seu próprio bem ou para o bem comum. Cf. TOMÁS DE AQUINO. ST I, q. 96, a.4, res.; ed. Leonina t.5, p. 430.

32 Sempre que existe uma combinação de elementos, contínua ou descontínua, para produzir uma realidade com unidade de composição, manifesta-se a dualidade do que governa e do que é governado; e isto, que acontece nos seres vivos releva de uma lei universal da natureza (...)" (ARISTÓTELES. Politica I, 1254a 28-31; trad. Amaral e Gomes, 1998, p. 63). Cf. TOMÁS DE AQUINO. ST I, q.96, a.4, res; ed. Leonina t.5, p. 430).
} 
Se o dominium político é considerado por Tomás como possível já no estado de inocência, no estado pós-pecado ele torna-se necessário, dada a mudança, pós queda, que ocorre na natureza humana:

o bem da natureza, que é diminuído pelo pecado, é a inclinação natural para a virtude, que é própria do homem pelo simples fato de ser um ser racional; pois é por isso que ele realiza ações de acordo com a razão, as quais são agir virtuosamente. Agora o pecado não pode tirar inteiramente do homem o fato de que ele é um ser racional, pois então ele não seria mais capaz de pecar. Portanto, não é possível que este bem da natureza seja inteiramente destruído (TOMÁS DE AQUINO. ST I-II, q. 85, a.2, res.; ed. Leonina, t.7, 1892, p. 111).

Vejamos que, segundo Tomás, apesar de a natureza humana ser afetada pelo pecado em suas inclinações, que passam, então, a ser tanto para a virtude quanto para o vício, conserva-se nela a razão e aquilo para que ela se inclina, incluindo a vida em sociedade . No entanto, como mencionado acima, a vida em sociedade não anula os comportamentos conflituosos e viciosos entre os homens, sendo necessária a existência de um governo que mantenha a paz e a unidade da estrutura social e dirija os homens a um bem comum $^{33}$.

\section{A teoria política de Tomás: um anúncio da modernidade?}

Segundo Habermas (1996) a reinterpretação operada por Tomás em relação a filosofia política aristotélica se configurou como um ponto central para a transformação da política clássica na filosofia social de Hobbes. É sabido que para Aristóteles a pólis não é uma mera união de homens que visam apenas relações de comércio ou de vida comum no âmbito da divisão de um mesmo território mas, ao contrário, ela é uma união que visa orientar seus cidadãos para a prática da virtude ${ }^{34}$. A pólis aristotélica é definida em oposição ao oikos, isto é, em relação as ações e relações, fundamentalmente de base econômica, que acontecem no interior da casa, no nível da sociedade familiar e da aldeia. Hobbes, por outro lado, está ocupado em tratar de uma comunidade voltada para suas bases econômicas de subsistência, como

\footnotetext{
33 TOMÁS DE AQUINO. De Regno I, 3; ed. Busa, 1954, np.

34 "A cidade subsiste para assegurar a vida boa." (ARISTÓTELES. Política, I, 1252b 28 1253a 2; trad. Amaral e Gomes, 1998, p. 53).
} 
o comércio entre os cidadãos, que necessita ser legislada pela soberania do Estado $^{35}$. De acordo com Habermas (1996, p. 91), Tomás é a figura mediadora entre essas duas visões distintas de comunidade política, pois ao mesmo tempo entende que, por um lado a cidade se forma com vistas no bem viver, o qual perpassa a esfera da promoção da virtude, na esfera pública, daqueles que são seus cidadãos, mas, por outro lado, percebe que ela não é uma comunidade essencialmente política, na realidade, antes disso ela é social, visto a natureza daqueles que a compõe. E, qual a implicação dessa constatação?

Como mencionado acima, para Tomás, o zoon politikon aristotélico é em primeiro lugar um animal social, antes de ser político. É claro que alguns leitores de Aristóteles podem dizer que a tradução de zoon politikon é, de fato, "animal social e político" e, que por isso, Tomás não anuncia nenhuma novidade. No entanto, não é exatamente na tradução que se centra a questão, mas no entendimento e no uso dos termos. Aristóteles, no livro I da Política, coloca de lados distintos a vida social que acontece no oikos e a vida política que acontece na pólis ${ }^{36}$. O primeiro, se refere ao âmbito dos interesses privados centrados principalmente na economia. O oikos é representado pelas estruturas sociais da casa e da família, as quais são ordenadas por um poder patriarcal, e visam suprir as necessidades básicas dos indiví$\operatorname{duos}^{37}$. O segundo, no caso a pólis, se refere ao âmbito público, regulado por um governo e responsável principalmente por promover a vida virtuosa daqueles que são considerados como cidadãos ${ }^{38}$. Tomás, ao contrário, aproxima os dois âmbitos através da ideia comum de sociedade. Como explica Bertelloni (2010, p. 24), através da reinterpretação do naturalismo aristotélico, Tomás apresenta uma natureza humana que não tem como fim principal o aperfeiçoamento ético e racional mas, na realidade, preza, em primeiro lugar, por atender suas necessidades básicas. Dessa maneira, enquanto Aristó-

\footnotetext{
${ }^{35}$ Cf. HOBBES. Leviathan, II, 24; ed. Waller, 1904, p. 179.

36 "A relevância de Aristóteles como paradigma da filosofia política clássica reside no fato de que ele se opôs fortemente à estrutura interna da esfera privada — o oikos — à esfera da esfera pública - a pólis." (BERTELLONI, 2010, p. 25). Sobre o assunto cf. também: ROY, 1999, p. 04.

37 “(...) a família é uma comunidade formada de acordo com a natureza para satisfazer as necessidades cotidianas.” (ARISTÓTELES. Política, I 1252b 12-13; trad. Amaral e Gomes, p. 51).

38 Ibid., 1252a 1-15; trad. Amaral e Gomes, 1998, p. 49.
} 
teles primava por uma comunidade política com vistas na promoção da virtude, a civitas, na teoria política de Tomás, se volta, em primeiro lugar, para as necessidades primordiais dos homens: "agora o bem-estar e a segurança de uma multidão formada em uma sociedade residem na preservação de sua unidade, que é chamada de paz." (TOMÁS DE AQUINO. De Regno, I, 3; ed. Busa, 1954, np). Além disso, se por um lado, para Aristóteles, o governo na pólis tinha como base as relações entre os cidadãos, no medievo de Tomás, diferentemente disso, o governo assume uma figura mais parecida com o domínio patriarcal que se passava no oikos. Nas palavras de Habermas,

A contraposição entre pólis e oikos foi nivelada sob o denominador comum de societas; [...] o thema probandum das reflexões da "política" tomista corretamente atribuídas a uma filosofia social, é pelo contrário, o de uma ordem doméstica e familiar que se estendeu para o Estado [...] (HABERMAS, 1996, p. 92).

É possível dizer que na interpretação de Habermas, a novidade de Tomás em relação a Aristóteles, está no fato de o Aquinate inserir o âmbito da economia, e as suas relações privadas, na civitas. Com isso, Habermas vê em Tomás uma figura central da transição entre a concepção clássica da política e sua perspectiva moderna. Ainda que Tomás continue fiel as bases aristotélicas, sua reinterpretação insere um novo paradigma ao medievo que, em certa medida, flerta com as discussões sobre Estado, poder e comércio desenvolvidas na filosofia política da modernidade. Para corroborar ainda mais com a percepção dessa mudança paradigmática, Habermas destaca o novo papel que a comunidade política assume em Tomás de Aquino, assunto que será amplamente discutido pelo professor Bertelloni em alguns de seus $\operatorname{artigos}^{39}$. Segundo Habermas, a civitas do medievo não tem o compromisso primordial de promover a virtude, como era o caso da pólis aristotélica, mas de garantir os requisitos básicos para a sobrevivência entre os homens.

\section{Conclusões}

A influência aristotélica na construção do pensamento político medieval tem sido tema de inúmeros estudos e discussões entre os historiadores da filosofia. Alguns, como Ullmann, são mais assertivos quanto ao papel

${ }^{39}$ Cf. BERTELLONI, 2003 e 2004. 
que Aristóteles teria exercido e o colocam como o grande responsável pela revolução no pensamento dos medievais. Outros, como Nederman, são mais críticos e tratam de demonstrar que, apesar da inegável presença do Estagirita, há muitas outras teorias envolvidas na construção da filosofia política medieval, assim como são muitas as reinterpretações dos textos de Aristóteles que antecedem sua chegada ao medievo. Entretanto, ainda que a recepção do filósofo na Idade Média se configure como um problema filosófico, isso não muda a forte presença de sua teoria naturalista na filosofia política de Tomás de Aquino.

A herança da filosofia antiga é confrontada com a realidade da sociedade medieval, como consequência se tem um distanciamento entre as doutrinas, e um novo paradigma desponta propondo teorias, como a de Tomás de Aquino, que anunciam temas da filosofia política moderna. Em Tomás, a reinterpretação do naturalismo aristotélico e sua combinação com outras teorias, como a do romano Cícero, propicia a construção de uma frutífera reflexão que se ocupa em discutir desde a origem da civitas, suas regras e leis, seu governo e as ações e relações humanas que ali acontecem. Com isso, a clássica visão da pólis aristotélica, espaço público da promoção da virtude, perde força e dá lugar a uma sobreposição de relações e interesses econômicos tidos, na antiguidade, como sendo parte do âmbito privado, isto é, do oikos. A civitas medieval, formada por homens, que antes de políticos são sociais por natureza, na visão de Tomás, passa a representar uma espécie de extensão da sociedade familiar (societas). Consequentemente, essa civitas, diferente da pólis aristotélica, assume a função de atender, em primeiro lugar, as necessidades básicas dos homens, dada a constituição ontológica de sua natureza e a estrutura da sociedade medieval, muito distinta do que se observava na Grécia Antiga.

Recebido em 05/01/2021 e aprovado em 01/01/2021

\section{Referências}

AURELli AUGUSTINI HIPPONENSIS. Opera omnia. Patrologice cursus completus, Series Latina, t. 32-47; ed. J.P. Migne, 1841-1849. 
AGOSTINHO, A cidade de Deus. $5^{\text {a }}$ ed. (3 vols). Tr., pref., nota biográfica e transcrições de J. D. Pereira. Lisboa: Calouste Gulbenkian, 2016.

ARISTÓTELES. Política. Edição bilíngue (português-grego). Trad. António Campelo Amaral e Carlos de Carvalho Gomes. Lisboa: Vega, 1998.

lo: Editora Madamu, 2020.

Ética à Nicômaco. Trad. Mário da Gama Kury. São Pau-

BERTELLONI, F. "La desaparición del fin virtuoso del orden político en la teoría política de la primera modernidade". In: XIV Jornadas De Iustitia et Iure. Buenos Aires, 2019. Naturaleza y Teoría Política en el Pensamiento Medieval y Renacentista. México: Universidade Panamericana, 2020, p. 2143.

"El tránsito de la sociedad a la politicidad en la Summa Theologiae de Tomás de Aquino" In: MARTINS, Manuel A. (coord.). Sociedade Civil - Entre miragem e oportunidade. Coimbra: Faculdade de Letras, 2003

. "Sociabilidad y politicitad (dominium) en la Summa Theologiae de Tomás de Aquino sobre la recepción tomista de la Política de Aristóteles". In: de BONI, L. A., e PICH, R., (orgs.), A recepção do pensamento greco-romano, árabe e judaico pelo Ocidente medieval. Porto Alegre: Edipucrs, 2004, p. 361-377.

" "La teoría política medieval entre la tradición clássica y la modernidade". In: ARNAS, Pedro Roche (org.) El pensamento político em la Edad Media. Madri: Editorial Centro de Estudios Ramón Areces, 2010, p. 17-40.

. Natura Multipliciter dicitur. Variantes em el uso del concepto de natura em la teoría política medieval a partir de la segunda mitad del siglo XIII. Scripta, Mendonza, vol. 4, no 2, p. 11- 30, 2011. Disponível em: http://revistas.uncu.edu.ar/. Acesso em: 02 dez.2020.

BOERI, M. D. "Natural Law and World Order in Stoicism". In: ROSSI, G. (ed) Nature and the Best Life. Exploring the Natural Bases of Practical Normativity in Ancient Philosophy. Hildesheim-Zürich-New York: G. Olms, 2013.

CHROUST, A.H. St. Augustine's Philosophical Theory of Law. Notre Dame Law. Review, vol. 25, 1950. p. 265-315. Disponível: https://scholarship.law.nd.edu/. Acesso em: 03 dez. 2020.

FERREIRO, J. La recepción del naturalismo político aristotélico en la explicación del surgimento del orden político en la Edad Media. 2010. 281f. Tese (Doutorado em Filosofia) - Facultad de Filosofía y Letras, Universidade de Buenos Aires, Buenos Aires. Disponível em: http://repositorio.filo.uba.ar/. Acesso em: 05 set. 2020. 
HABERMAS, Jürgen. Teoria e práxis: estudos de filosofia social. Trad. Rúrion Melo. Ed. Unesp, 2013

MARTINS, J. A. Sobre as origens do vocabulário político Medieval. Trans/Form/Ação, Marília, vol.34, no.3, 2011. Disponível em: https:// www.scielo.br/. Acesso em: 02 ago. 2020, n.p.

M. TULLI CICERONIS. De Legibus libri Tres. Editit C.F.W. Mueller. Lipsiae: Teubner, 1915.

. Scripta quae manserunt omnia. fasc. 43. De finibus bonorum et malorum. Recognovit T. Schiche. Leipzig: Teubner, 1915.

. Scripta quae manserunt omnia. Fasc. 2. Rhetorici libri duo. De Inventione. Recognovit E. Stroebel. Leipzig: Teubner,1965.

NEDERMAN, C. J. Nature, Sin and the Origins of Society: The Ciceronian Tradition in Medieval Political Thought. Journal of the History of Ideas. Pennsylvania, vol. 49, no. 1, p. 3-26, Jan. - Mar., 1988. Disponível em: https://www.jstor.org/stable/2709701. Acesso em: 05 nov. 2019.

. The Meaning of "Aristotelianism" in Medieval Moral and Political Thought. Journal of the History of Ideas, (S.1), vol. 57, no. 4, p. 563-585, oct., 1996. Disponível em: https://www.jstor.org/stable/ 3654082. Acesso em: 03 out. 2019.

. Aristotelianism and the Origins of 'Political Science' in the Twelfth Century. Journal of the History of Ideas, (S.1), vol. 52, no. 2, p. 179-194, 1991. Disponível em: www.jstor.org/stable/2709524 . Acesso em: 28 fev. 2021.

ROY, J. 'Polis' and 'Oikos' in Classical Athens. Greece \& Rome. Nova York, vol. 46, no. 1, p. 1-18, 1999. Disponível em: https://www.jstor.org/stable/ 643032. Acesso em: 25 fev. 2021.

SANCTI THOMAE DE AQUINO. De regno ad regem Cypri. Ed. Roberto Busa e Enrique Alarcón. Textum Taurini, 1954.

- Quaestiones disputatae de malo. In: . Opera omnia. Roma- Paris: Textum Leoninum, 1982.

- Pars Prima Summae Theologiae. In:__. Opera omnia. Roma: Textum Leoninum, $1888-1889$.

. Prima secundae Summae Theologiae.

In:__ . Opera omnia. Roma: Textum Leoninum, 1891 - 1892.

Sententia libri Politicorum. Ed. Roberto

Busa e Enrique Alarcón. Textum adaequatum Leoninum, 1971. 
SKINNER, Q. As fundações do pensamento político moderno. $1^{\mathrm{a}}$ ed. Trad. Renato Janine Ribeiro e Laura Teixeira Mota. São Paulo: Companhia das Letras, 1996.

TOMÁS DE AQUINO. Do governo dos príncipes ao Rei de Cipro. Trad. Arlindo Veiga dos Santos. São Paulo: Edipro, 2013.

. Suma Teológica. $2^{\mathrm{a}}$ ed. Coord. Carlos Josaphat Pinto de Oliveira OP, trad. Aldo Vannuchi et al. São Paulo: Edições Loyola: 2010.

THOMAS HOBBES. Leviathan; or, The matter, form and power of commonwealth, ecclesiastical and civil. Ed. WALLER, A. R. Cambridge: University Press, 1904.

ULlMANN, W. Historia del pensamiento político en la Edad Media. Trad. Rosa Vilaró Piñol, Barcelona: Ariel, 1983.

. Law and politics in the Middle Ages: an introduction to the sources of medieval political ideas. Cambridge University Press, 1975.

Principles of Government and Politics in the Middle Ages. $3^{\mathrm{a} e d . ~ N e w ~ Y o r k: ~ R o u t l e d g e ~ R e v i v a l s, ~} 2010$. 